\title{
LITERATURA E EDUCAÇÃO: CONHECIMENTOS E AFETOS EM MEMÓRIA A CRISTINA MELLO
}

\section{LITERATURE AND EDUCATION: KNOWLEDGE AND AFFECTION IN MEMORY OF CRISTINA MELLO}

Literatura, educação, ensino, recepção e circulação são palavras-chave que atravessam o presente dossiê. Ao todo, são vinte artigos a convidar leitores e leitoras para uma imersão nas três vertentes do sistema didático: o professor, os alunos e o saber ensinado (CHEVALLARD, 1991). Antes de apresentar as contribuições de professores/as e pesquisadores/as da área, gostaríamos, na condição de organizadoras do dossiê, de prestar a nossa homenagem para a professora e pesquisadora Cristina Mello, a quem dedicamos este número. Natural de Londrina e residente em Portugal desde 1978, licenciou-se em Letras pela Universidade Estadual do Rio de Janeiro em 1977, fez mestrado e doutorado no Porto e Coimbra, respectivamente. Nesta última instituição, começou a lecionar em 1987. Dentre as obras de sua autoria, destacamos $O$ ensino da literatura e a problemática dos gêneros literários (1998), que se tornou referência básica para alunos, professores e pesquisadores da área de ensino de literatura.

Optamos por apresentar as discussões propostas nos artigos elencados em diálogo com as memórias que permeiam a nossa convivência com a professora Cristina Mello em momentos distintos, porém marcantes de nossas trajetórias pessoais e acadêmicas. Os diálogos e as partilhas com ela alargaram a nossa compreensão sobre o ensino da literatura. Logo, organizar um material que envolve temas sensíveis da área remete-nos para uma saudosa memória afetiva de quem tanto nos ensinou e que partiu deixando um imenso legado. Inclusive, a sua contribuição direta e efetiva para a Revista Graphos, da qual fez parte da equipe editorial. As aulas e os diálogos com a professora Cristina Mello tiveram desdobramentos em nossa prática docente e suscitaram inúmeras reflexões diante dos desafios que se lançam, cotidianamente, no domínio das relações entre saberes teóricos e experienciais.

Eu, Rinah, tive a imensa satisfação de tê-la como professora na disciplina Ensino da Literatura II, unidade curricular do programa de doutoramento em Literatura de Língua Portuguesa: investigação e ensino da Faculdade de Letras da Universidade de Coimbra. Em um dos últimos $e$-mails que trocamos, ainda na época da disciplina em que fui sua aluna, em 2010, ela devolvia uma resenha escrita por mim: "prezada Rinah, devolvo-lhe o texto, com algumas notas a vermelho. Em alguns casos são indicações para corrigir, em outros, aspectos para pensar". O convite generoso à reflexão era um traço característico de sua prática docente. 
Lembro-me de textos poéticos que líamos em sala e estimulavam posterior discussão sobre contextos educativos e práticas de leitura. Cito dois deles: "Isto", de Fernando Pessoa e "Misere Nobis”, de Miguel Torga. "Conhecer a literatura e conhecer com a literatura”: uma máxima que nos fazia pensar sobre práticas de ensino de literatura sem jamais lançar mão do saber ensinado, a literatura, e da centralidade de noções que compõem esse campo de estudo: a observação, as experiências e as práticas.

“Sentir! Sinta quem lê!". Da leitura dos versos pessoanos mediada por ela ficam as lições - pelas quais serei eternamente grata - sobre o lugar do sentir no encontro com o texto literário aliado a uma escuta sensível. São aspectos que preservo, cuidadosamente, em minhas práticas, apesar dos fatores de desperdício de experiências que comprometem os processos de formação de leitores e que seguem potencializados em contexto pandêmico: excesso de informação, falta de tempo, excesso de opinião e outros mais que o educador Jorge Larrosa Bondía (2002) discute, ao pormenor, em um de seus ensaios sobre experiência.

Eu, Marta, encontrei Cristina por meio da pesquisa acadêmica, quando participamos, juntamente com outros pesquisadores, de reuniões de trabalho promovidas pelo Programa de Pós-graduação em Estudos da Linguagem da UFRN por ocasião da implantação da Linha de Pesquisa Leitura do Texto Literário e Ensino e de parcerias institucionais que se consolidavam entre a UFRN e a Universidade de Coimbra. Afinidades de pesquisa, afinidades de lugares e pessoas e uma afabilidade que se tornou amizade e se fortaleceu nas diversas oportunidades em que estivemos juntas, em Natal, Coimbra e Santarém. Lembro que um espaço que Cristina Mello fez questão de percorrer e conhecer foi o da Biblioteca Zila Mamede que para ela, "além de local de obtenção de conhecimento, a biblioteca se afigura como uma alternativa à ocupação inteligente do ócio". Para Cristina, "os espaços da biblioteca não deixam de ser um agasalho e um aconchego à solidão, tendo em vista a possibilidade de convívio humano, mesmo que na comunhão do silêncio a que a leitura convida".

Silêncio.

Este dossiê, por exemplo, é fruto de uma potente experiência: a IV Jornada de Literatura e Educação e I Simpósio Internacional Literatura e Educação. O evento científico interinstitucional (UFPB, UNICENTRO, UFES, USP, UFRJ, UFSP, UPF, UNESP, UFCG, UNIFESP) aconteceu na Universidade Federal da Paraíba, em João Pessoa - campus I, nos dias 27 e 28 de agosto de 2019, sob coordenação da Professora Daniela Segabinazi (UFPB/DLCV/PPGL). Os sete primeiros artigos do dossiê trazem um tanto dessa memória que nos é tão cara, pois são de autoria de professores/as e pesquisadores/as que estiveram conosco 
durante dois dias intensos de fóruns de discussões, mesas-redondas, conferências e fóruns de pesquisa com apresentação de trabalhos de graduação e pós-graduação.

Lembramo-nos da abertura do evento. Na altura fazia sete meses da partida da nossa querida professora Cristina Mello. E lá estávamos nós, colegas de área, trazendo à tona problemáticas sobre as quais ela dedicara boa parte de sua trajetória de vida. Impossível não recordar suas valiosas lições. Cristina, presente! Uma delas, por exemplo, envolvia a representação do ensino de literatura na educação contemporânea, tópico contemplado pela professora Neide Rezende no artigo "Da análise técnica a leitura literária: abordagens da literatura na escola", que traz uma valiosa contribuição para a discussão sobre as diferentes perspectivas de ensino da literatura no Brasil, de forma crítica e situada. Destaco, sobretudo, o tópico "quando a recepção da literatura se encontra com os estudos culturais", que lança olhares sobre os entrelaçamentos entre "lutas sociais, produção cultural e produção acadêmica". Ressaltamos ainda o fato de o texto contemplar o lugar da experiência docente no Ensino Médio a partir de uma prática de mediação de leitura do romance A hora da estrela, de Clarice Lispector. Ou seja, trata-se de um importante contributo para a caracterização de tendências e modos de abordagem do ensino da literatura e das pesquisas da área, alguns dos tópicos recorrentes nos debates em sala de aula com a homenageada deste dossiê.

Nesse sentido, também os artigos "Democracia e pobreza em pesquisas brasileiras sobre educação literária", de Maria Amélia Dalvi e "É proibido proibir? Vetos à literatura em tempos conservadores", de Ana Crélia Dias, apresentam o viés ético e político da educação literária, que alude à pergunta/provocação feita, assertivamente, pela professora Cristina Mello: “serventia ou servidão da literatura?”. Em seu texto, por exemplo, Dalvi corrobora tal reflexão ao problematizar o debate ainda incipiente sobre democracia e pobreza em pesquisas da área, “a quem e a que isso tem interessado?”. Uma inquietação partilhada por muitos de nós que acreditamos no direito à literatura, à luz de Antonio Candido (2011), e o defendemos. Um direito que segue ameaçado pelo ultraconservadorismo e pela sanha do veto aos textos literários na contemporaneidade. A "censura travestida de adequação" - pedras no caminho do exercício de alteridade promovido pela leitura literária, sobre as quais Dias se ocupa concretamente em seu artigo, na medida em que compreende os enfrentamentos pela via coletiva como possibilidade de resistência contra os retrocessos apurados e que fragilizam ainda mais o ensino de literatura em contexto escolar.

A respeito das fragilidades que atravessam o contexto da literatura e educação, em "Notas sobre os documentos oficiais e o ensino de literatura na educação básica no Brasil”, João Batista 
Pereira não só apresenta um panorama histórico do (não) lugar do ensino da literatura na educação básica sob a perspectiva das leis nacionais e dos documentos parametrizadores, mas propõe reflexões sobre os fatores que inibem avanços significativos na formação de leitores no Brasil. Um deles está relacionado com a falta de articulação entre as teorias vistas nos cursos de formação docente e a realidade encontrada no chão da escola pelos alunos. Ao destacar este "desencontro", Batista ativa a nossa memória das discussões prolongadas e estimulantes promovidas em sala de aula pela professora Cristina Mello sobre os modos de aproximação à literatura na "era do vazio" (LIPOVETSKY, 2005), a defesa da literatura como uma prática cultural, da inseparabilidade entre educação e cultura e a necessidade de aproximar a cultura da educação. Ao ativar essa lembrança, podemos dizer que o referido artigo, portanto, nos estimula também a pensar coletivamente sobre a formação cultural dos jovens, ávidos leitores de obras pouco reconhecidas institucionalmente e as implicações nada (pro)positivas decorrentes dessa falta de legitimação como fatores que afetam diretamente a construção de comunidades leitoras.

O artigo "Práticas de ensino de literatura e de leitura literária", de Gabriela Rodella de Oliveira, dialoga com o texto anterior pela dimensão propositiva e autorreflexiva que abarca. Nele a autora discorre sobre a formação de comunidades leitoras, metodologias e práticas que perpassaram a sua trajetória desde quando era aluna do curso de Letras até as experiências como professora e pesquisadora. O viés memorialístico - igualmente contemplado nesta homenagem - lança-nos algumas luzes sobre a reconfiguração contemporânea de alternativas pedagógicas e como as interações entre sujeitos e as trocas verbais como fatores de aprendizagem podem dar o tom da construção do conhecimento no domínio da literatura e educação.

As interações e aprendizagens no campo das práticas de leitura literária têm lugar no artigo de Carmen Sevilla Gonçalves dos Santos intitulado "Atos de ficcionalizar e emancipação do leitor: para além do oxigênio". O texto soma-se ao conjunto de propostas até aqui elencadas na medida em que reitera, a partir do diálogo com as teorias iseriana e vigotskiana, a dimensão humanizadora, logo antropológica, da literatura e dos atos de ficcionalizar.

A autora ilumina algumas questões epistemológicas a respeito do ensino da literatura hoje e suas possibilidades de configuração, nos fazendo retomar um aspecto crucial apontado pela professora Cristina Mello: "a investigação em educação deve sustentar um conhecimento organizado e sistemático, envolvendo as práticas de ensino". Isso se desvela no texto, sobretudo quando Santos destaca a importância da mediação de um mapeamento da experiência estética, que pressupõe a interação texto-leitor, e traz o trabalho com o Roteiro Didático Metaprocedimental (RDM) como exemplo. Ou seja, a consciência da experiência estética pode 
ser alcançada com base nessa organização que visa a emancipação leitora e, pela forma como se apresenta, possibilita formas de reconfiguração do campo educativo que mantemos em foco neste dossiê.

O sentido identitário que permeia a dimensão antropológica da leitura literária, teoricamente contemplada no artigo anterior, é reiterado em "Caminhos para a leitura literária em língua francesa na educação infantil”, de Josilene Pinheiro-Mariz. Dessa vez, sob a perspectiva do percurso afirmativo da lei 10.639/03 e a partir do lugar da leitura literária na formação cultural de crianças e jovens para a ampliação de seus horizontes linguísticos e culturais fomentada pelo encontro com a literatura africana de língua francesa, na qual o protagonismo feminino tem se destacado, como nos revela a referida pesquisa. Portanto, tratase de um texto que corrobora a perspectiva decolonial de ensino da língua e da literatura, na medida em que o defende - pela via integradora - como um dos caminhos para acessar a pluralidade de saberes e as mais diversas formas de ser e estar no mundo.

Os três artigos seguintes dialogam entre si, pois tratam de recepção e mediação de processos de leitura no ensino a partir dos livros ilustrados e de imagem. No texto "Lendo Vozes no Parque, de Anthony Browne - um estudo da recepção por crianças de diferentes contextos", as autoras Rosa Hessel, Darlize de Mello e Liége Barbosa nos convidam a pensar sobre a recepção de leitura em diferentes contexto socioculturais, partindo das seguintes perguntas: "como crianças de diferentes realidades respondem a um mesmo livro ilustrado, por sua vez produzido em outro continente?; o que os dados destes gestos de leitura podem nos ensinar sobre uma mediação adequada em relação a livros ilustrados?”.

Em “O gato e a árvore - cuidados na formação do leitor de imagem”, Flávia Brocchetto Ramos, Fabiana Lazzari Lorenzet e Renata Junqueira de Souza discutem e situam conceitualmente narrativas visuais de acervos de Educação Infantil que compõem o Programa Nacional Biblioteca da Escola (PNBE) 2014. Além disso, compartilham uma experiência de mediação do livro de Rogério Coelho, concebendo-o como "objeto cultural que pode gerar autonomia, interação e liberdade de compreensão entre os pequenos estudantes". Concluímos o bloco dedicado ao texto visual - literário com o artigo "Proposta didática para a mediação da leitura de um livro de imagem", no qual Marilia Forgearini Nunes apresenta uma sugestão de abordagem didática do livro A menina e o tambor, de Sônia Junqueira e imagens produzidas por Mariângela Haddad, com base na semiótica discursiva e semiótica plástica.

Os três últimos artigos mencionados, portanto, têm em comum a intenção de refletir sobre a questão do letramento visual e do professor - mediador no trabalho com as narrativas visuais, 
de modo que a imagem e a ilustração não sejam concebidas como meros adornos, mas sim a partir de suas especificidades de linguagem e potencialidades interativas que geram sentidos/significados múltiplos.

A esse conjunto de proposições soma-se o artigo "O fim da literatura: possibilidades de enfrentamento". O autor Diego Gomes do Valle se utiliza do campo da crítica e do ensino da literatura para assegurar os revides e transmutar o fatalismo dos prenúncios do fim em finalidades que preservem o fator humanizador da literatura e sua potência. Com o intuito de elucidá-los em diálogo com os estudos convocados, o texto traz uma análise do poema "O monstrengo", de Bruno Tolentino.

No artigo "A leitura literária como direito humano: experiências de leitura compartilhada em bibliotecas comunitárias do Cirandar”, Renata Toigo e Regina Kohlrausch partem da convicção de que a literatura é um direito humano básico e apresentam, como exemplo de compromisso de formação leitora e de letramento literário, as ações realizadas nas bibliotecas comunitárias do Centro de Integração de Redes Sociais e Culturas Locais - Cirandar. As autoras ressaltam que a importância dos espaços comunitários para a garantia do acesso à literatura é fundamental e nos levou mais uma vez a memorarmos algumas reflexões propostas por Cristina Mello quando da sua participação nos Diálogos do $6^{\circ}$ Seminário Internacional de Bibliotecas Públicas e Comunitárias na mesa de debates "Bibliotecas públicas e seus desafios para a construção de uma sociedade leitora" onde exemplificou práticas de leitura na biblioteca para a construção da cidadania, reforçando que as bibliotecas são portais de acesso ao conhecimento, "designadamente no que diz respeito a uma oferta de serviços diversificada, atualizada, acessível à comunidade".

Conforme assinalou Cristina, "falar de bibliotecas e formação leitora é um assunto que deve ser considerado de grande relevância política, social e cultural” (MELLO, 2014, p.10) e avigorando a questão, Maria Luzineide P. da Costa Ribeiro estende esse pensamento ao reunir no artigo "Recortes da prisão: um mosaico de experiências literárias nas prisões federais brasileiras" os relatos e depoimentos de leitores encarcerados, apresentando recortes da prática literária na prisão, por meio de relatos e depoimentos de leitores em situação de cárcere. A figura desse leitor, o seu comportamento e os impactos da sua prática de leitura são analisados no estudo que ora apresentamos, constituindo experiências que, conforme propõe a autora, confirmam a prática da leitura na prisão como atividade emancipadora e reforçam a relevância da leitura no cárcere para além da ideia de remição de pena. 
Já no trabalho de Patricia Machado, denominado "Nos tentáculos da indústria cultural: estratégias contemporâneas que ativam novas práticas de leitura", a autora problematiza a dinâmica de atuação do mercado editorial que, através de grandes investimentos publicitários, incentiva a proliferação de livros com atributos que aguçam uma literatura desejável, repetitiva e previsível. Segundo a autora, desse tipo de leitura pode decorrer um discurso simplista geralmente acoplado a outros produtos culturais altamente vendáveis, observando que uma coisa é o valor literário de uma obra e outra é o papel que ela pode desempenhar na formação de leitores. Nesse sentido, são problematizados os mecanismos e práticas de produção, circulação e consumo literário proporcionados pelo mercado editorial, associados à indústria cultural, cinematográfica e do entretenimento e suas reverberações na formação leitora.

Na mesma direção, o estudo de Luzimar Silva de Lima e Shirlei Marly Alves denominado "Best-seller e ensino de literatura: o mercado editorial, os leitores e a escola" problematiza o uso dos best-sellers como ferramenta para a formação leitora. Entendendo a literatura enquanto prática de liberdade, as autoras discutem as escolhas dos leitores permeadas por questões como: conceito de cânone e implicações com os best-sellers, cultura de massa, repertório de leituras do jovem leitor, dentre outras que envolvem "a necessidade de um olhar para a arte literária a partir das perspectivas política e democrática quando a questão é leitura literária na escola", suscitando a lembrança de várias das discussões realizadas durante o Simpósio "Educação literária e ensino da literatura no básico e secundário" que Cristina Mello coordenou juntamente com Pedro Balaus Custódio durante o VI Simelp.

Trazendo ainda à memória uma conferência realizada por Cristina Mello no auditório da Escola de Música da UFRN, na qual ressaltou que uma preocupação nos debates em torno da leitura literária é a questão da motivação e do prazer de ler, Arlene Batista da Silva no artigo "Dos cânones ao mangá: indicações de leitura dos estudantes de Letras e Pedagogia" aborda as indicações de leituras literárias feitas por graduandos iniciantes dos cursos de Letras e Pedagogia, mapeando experiências de leitura literária dos graduandos, os gostos, as condutas, as concepções de leitura literária e de literatura, bem como as forças que convergem na construção dessas representações, e que evidenciam a influência de diferentes campos na formação literária desses sujeitos. Em caminho paralelo, tomando como base o conto "A cartomante", de Machado de Assis, Sheila Oliveira Lima e Franciela Silva Zamariam no estudo "RPG e Literatura na escola: leitura, afeto e negociações de sentido" apresentam uma proposta para a formação de leitores na educação básica por meio de metodologia estruturada a partir do 
diálogo entre a prática da leitura e a vivência do RPG, evidenciando, assim, pontos de contato entre os fenômenos do jogo e da leitura.

Aproximar o estudo da literatura e a vivência cotidiana dos alunos também foi a proposta de Philio Generino Terzakis, no estudo "Narrativa, narrativas e ponto de vista: anotações para um ensino explícito da literatura" ao realizar a leitura e análise do conto "A casa de Astérion", de Jorge Luis Borges, em uma proposta de aula de literatura baseada na metodologia do ensino explícito. A proposta foi direcionada aos alunos do curso de Letras Estrangeiras Modernas, que apresentavam dificuldades de leitura e escrita e pouca prática de leitura de textos literários, abalizando, portanto, que a leitura literária é fundamental para o desenvolvimento humano e que o "ensino de literatura deve basear-se na efetiva compreensão dos textos por parte dos alunos" (MELLO, 1998, p. 317).

Em seguida, adentrando à história da literatura infantil e juvenil brasileira e tendo como proposta uma abordagem histórico-contextual a respeito dos livros de leitura nos fins do século XIX e na primeira metade do século XX, cujo corpus de análise é o Livro I da Série Braga, Cristiano Camilo Lopes apresenta, no artigo denominado "Os livros de leitura no fim do século XIX e início do século XX: uma análise do Livro I da Série Braga e a formação do leitor literário" uma acurada apreciação de temas que estiveram presentes na educação como família, escola e pátria, no período citado. A proposta de Cristiano Camilo foi captar subsídios para a avaliação da trajetória, bem como para a avaliação dos caminhos da leitura literária na escola desde a primeira metade do século XX, sinalizando que a escola foi colocada como o elemento intermediário que serviu de extensão da família e que teve a missão de preparar cidadãos para a república que se formava nas primeiras décadas do século XX.

$\mathrm{E}$, finalizando o dossiê, temos o estudo "O que revelam os resultados de avaliações externas sobre o ensino da literatura na formação docente?” de Juliana A. B. Menezes, que parte da premissa de que bons resultados não necessariamente revelam boas práticas do ensino de literatura. Tal afirmação decorre da análise da prática de ensino de literatura em duas escolas, sendo uma pública e outra privada, que apresentaram bons desempenhos em avaliações externas, como o ENEM. Para tanto, a autora apresenta o conceito de leitor anárquico, ou seja, "aquele que lê com o olhar libertário das amarras sociais e poderá ser formado, a partir de uma escola democrática que enxergue a leitura literária como uma prática social e um ato político".

Em 2004, em seu artigo "Paradigmas literários e o ensino da literatura hoje (MELLO, 2004b), Cristina Mello já nos alertava sobre as implicações de "tempos de resistência ao pensamento problematizante" (MELLO, 2004b, p.26). Nesse sentido, em uma das várias 
palestras ministradas por ela nas parcerias e intercâmbios institucionais Brasil/Portugal, como pesquisadora atenta às demandas sócio-político-culturais que envolvem a prática docente de ensinar literatura e desenvolver a leitura, afirmava que: "A leitura serve, a meu ver, principalmente para estimular o pensamento - onde reside o cerne que fundamenta uma educação que se pretenda desenvolvida" (MELLO, 2004a, p.140-141). Assim, podemos dizer que a voz da professora Cristina Mello se soma às vozes que compõem este dossiê, pois, juntas, fazem ressoar a paixão pela Literatura ao mesmo tempo em que apontam caminhos para mantêla indissociada da educação. Afinal,

[n]um momento em que vivemos uma grande apatia profissional em virtude do descrédito da educação (o maior bem público das nações), talvez valesse a pena começar por nos interrogarmos acerca do alcance e das finalidades dos saberes, dos valores e das competências no quadro de uma educação para a cidadania (MELLO, 2004b, p.27).

Com essas palavras, gostaríamos de finalizar nossa homenagem à mestra, colega de profissão, pesquisadora, amiga, pessoa sensível e querida Cristina Mello, que partiu muito cedo, legando-nos a herança de um amor grandioso pela Literatura e seu ensino, que se refletiu em seus ensinamentos, nas aulas, nas pesquisas e publicações ao longo da sua carreira docente.

Boa leitura!

João Pessoa, 30 de setembro de 2020

Marta A. G. Gonçalves

Rinah de Araújo Souto

Organizadoras do Dossiê

\section{Referências}

BONDÍA, Jorge Larrosa. Notas sobre a experiência e o saber de experiência. Revista Brasileira de Educação [online]. 2002, n.19, pp.20-28.

CANDIDO, Antonio. Vários escritos. 5 ed. Rio de Janeiro: Ouro Sobre Azul, 2011.

CHEVALLARD, Yves. La transposition didactique du savoir savant au savoir enseigné. Grenoble: La Pensée Sauvage, 1991.

LIPOVETSKY, Gilles. A era do vazio. Barueri: Manole, 2005.

MACHADO, Ana Maria; MELLO, Cristina. Introdução. Revista de estudos literários, v.3, Coimbra, CLP, 2013. 
MELLO, Cristina. O ensino da literatura e a problemática dos géneros literários. Coimbra: Almedina, 1998.

MELLO, Cristina. Da centralidade do processo de leitura no debate atual sobre a formação do leitor: construção de estratégias pragmáticas e sua aplicação didáticopedagógica. In: Leitura, identidade e patrimônio cultural. Passo Fundo, RS: Editora UPF, 2004a.

MELLO, Cristina. Paradigmas literários e o ensino da literatura hoje. Vértice, n. 120 (novembro-dezembro), 2004b. pp.13-37. 